\title{
FOCUS ON CURRICULUM TRANSFORMATION THROUGH EDUCATOR AND STUDENT ATTITUDE DEVELOPMENT TO DIGITAL COMPETENCE
}

\author{
Irēna Žogla \\ Rezekne Academy of Technologies, Latvia \\ Svetlana Ušča \\ Rezekne Academy of Technologies, Latvia \\ Mihails Kijaško \\ Rezekne Academy of Technologies, Latvia
}

\begin{abstract}
Huge quantities of information processed through the use of digital technologies occupy an increasing place in education and trigger a search for understanding of the essence of speedy changes in order to capture the most productive ways of monitoring them. Investigations indicate that the goals of education in general which dominated at the beginning of the $21^{\text {st }}$ century have shifted from an accent on disciplinary knowledge of facts to an in-depth understanding of scientific ideas and concepts and to higher order thinking of educators and students which are integrated with the transformational impact of technologies. Curricula offer students innovative knowledge and tools for deeper understanding and implementing digital technologies, as well as emphasize the development of creativity (Chai, \& Kong, 2017). Meanwhile, the educators' attitudes to technologies that have become decisive educational tools differ across countries, cultural settings and universities. Even more, educators and students identify differences in their attitudes towards the digital technologies and their usage. Much of the students' possible success in digital competence development depends on the educators' attitude to the evolving amount of technologies to achieve a deep understanding of its transforming nature and appropriate changes of curricula. An effective usage of technologies for educational purposes, therefore, needs constant investigation to balance out all that constitutes the inseparable parts of education at its tertiary stage and thus keep targeted the transformational process.

The present paper uses the data collected by the project "Implementation of Transformative Digital Learning in Doctoral Program of Pedagogical Science in Latvia" (LZP-2018/2-0180) to trace if there are any significant differences in educators' and tertiary students' attitudes to digital technologies (Gokhale et al., 2013; Hofstede et al., 2011) and competence development, that might interfere with the transforming nature of technologies and the improvement of the digital competence of students.
\end{abstract}


The paper presents for discussion the possible developments of the didactic principles that form a background for creating a model of educators' attitude development in further learning. These can be grouped around the three quality levels of the digital competence, that highlight their essence and transformative character: (a) instrumental competence as an ability of completing one's job, (b) mastery level of one's competence and (c) educators' expert's level or even excellence in creative innovations that promote the development of a tertiary institution or tertiary education in general. The foundations of educator attitudes to digital technologies and their usage are discussed, as well as the transformational and transformative character of digital technologies that interfere with educator attitudes, general and unique qualities which a tertiary curriculum aims to nurture and that educator further learning helps to keep balanced.

Data analysis and the associated theoretical assumptions present a theoretical and methodological background for further investigation by the above - mentioned projects.

Keywords: educators, digital competence, attitude, gender and age differences, curricula transformation.

\section{Introduction}

Despite the growth of technology in universities, findings of investigations (Al-Musawi et al., 2013) conclude that universities have been slow to bring e-learning into the mainstream and maximize the benefits of digital learning for students. Usually, investigations are directed at the students' digital competence and state that some of them still hold underdeveloped e-learning skills. The educators' attitude towards e-teaching and e-learning also attracts the researchers' attention and need to be considered to catch up with vast quantities of information which is suggested and processed through digital technologies. These occupy a growing place in education and trigger the search for understanding of the most productive ways for their monitoring. We mention only some essentials to introduce this study:

(a) Investigations indicate that the goals of education in general, and of computer sciences in particular, which dominated at the beginning of the $21^{\text {st }}$ century have shifted from the accent on disciplinary knowledge of facts to in-depth understanding of scientific ideas, concepts and high order thinking of educators and students that are integrated with the transformational impact of technologies.

(b) University curricula provide students with innovative knowledge and tools for deeper understanding and implementing digital technologies, as well as emphasize the development of creativity (Chai, \& Kong, 2017), but the speedy progress of digital technologies, for instance, the 5G network (Segan, 2018; Hoffman, 2019) cannot be caught up to by the slow development of educator digital competence, especially if competence is defined in stale categories and restricted by their attitudinal development in general. 
(c) Meanwhile, the educators' and students' attitudes to technologies as educational tools differ even within one university; educators and students identify differences in their attitudes towards digital technologies and their usage.

Much of the students' possible success in digital competence development depends on the educators' attitude to the evolving speed and amount of technologies, as well as changes to the study content and productive usage of the available equipment to achieve a deep understanding of its transforming nature and appropriate changes of the educational process. Therefore an effective usage of technologies for educational purposes needs constant investigation to keep in balance all that constitutes the inseparable parts of education at its tertiary stage.

The aim of the research: to analyze commonalities and possible differences in the assessment of students' and educators' attitudes towards digital technologies, reasons for their usage, and, if possible, identify motivation to improve their digital competence in order to embrace possibilities of curricula transformations. The researchers did not aim for a large number of respondents - it is more important to identify precedents and learn about the character of students' and learners' attitudes if these provide opportunities to reach the appropriate level of competencies.

Analysis of the collected empirical data and associated theoretical assumptions present a theoretical and methodological background for further investigation by the project that is mentioned above.

\section{The background knowledge}

The researchers employ the definition which conceptualizes attitude as a psychological construct, a force or quality of mind, a mental and emotional entity that inheres in or characterizes a person (Perloff, 2016). According to Allport (1935), the importance of educators' and students' attitude sits in the specific nature and functioning of attitudes. Several qualities and aspects of attitudes - intercultural, creative, critical, autonomous, responsible (Ala-Mutka, 2011; Martin \& Grudziecki, 2015; Redecker, 2018) conform with studies in the digital age and therefore are of special importance in curricula building:

- numerous investigators confirm many aspects including a mental association between an object of the attitude formed and its evaluation (Fazio, 1989, 155), the favor or disfavor expressed by evaluating the object of the attitude;

- being related to motivation or a state of readiness for activities, attitudes influence thoughts, feelings and actions, therefore are linked to a person's core values; 
- attitudes are never directly observable, but being real and substantial ingredients in human nature, they become impossible to account satisfactorily either for the consistency of an individual's behavior or for the stability of any social or cultural context;

- attitudes appear in actions, communication, and cooperation when learning by doing is an appropriate situation to demonstrate, share and further develop ones' attitudes;

- in the mobile world with speedy technological progress, attitude as a human construct responds to the external changes through its accessibility - attitude is learned, comes quickly to one's mind and influences decision-making.

Due to these qualities, attitudes deserve to be investigated to address and develop educator and student responsibility, the quick targeted reaction to constant external changes, and for triggering curricula development. These peculiarities allow the researchers to treat educators' and students' attitudes as an influential force which, if coupled with the transformational character of the digital technologies, should be used for targeted curricula re-direction towards effective tertiary studies appropriate for 21st Century creative autonomous learning and competencies.

Several interrelated phenomena and categories often appear in documents and research that need to be acknowledged and used in education. These are digital competencies, 21st Century learning, appropriate curriculum transformations, and accordingly updated understanding of pedagogy, especially its constant and changable components (Žogla, 2017). The new educational possibilities of the digital age challenge educators' attitude development through encounter with new knowledge, identifying its importance, ways and targeted activities of introducing appropriate transformative innovations adequate to the students' needs.

Digital competence should be considered transversal and therefore need to be defined and treated appropriately to create tertiary and educators' further learning curricula with a respect towards the role of competencies in attitude development and the power of attitudes to inspire competence development. Competencies are directly linked to student and educator success and their positive attitude to teaching and learning. Clear definitions (of attitudes and competencies) are needed on which to base investigations and education, to search for technology-based interactive devices and for systems to support learning even at the tertiary level, which combines real and digital worlds (Sanabria \& Arámburo-Lizárraga, 2016) regarding innovative services for human-computer interaction (Lytras et al., 2016). Competencies are usually defined as a system of knowledge and skills being implemented in activities or a system of professional and pedagogical competence leading to a quality of a transversal competence and facilitating 
learners' digital competence. It is most important that the focus is not on the technical skills and instrumental competence, rather, the framework aims to specify how digital technologies can be used to enhance and innovate education (EC, 2019). The transformative impact, speed, and scope of digitalization challenges educators' and students' motivation and attitude to technologies, developing the educational process, and appropriate achievements.

Under the auspices of the Joint Research Centre, Institute for Prospective Technological Studies of the European Commission, digital competencies are conceptualized as a broadly defined phenomenon that reflects one' confidence, critical and creative use of information and communication technologies to achieve goals related to work, employability, learning, leisure, inclusion and/or participation in society (Ala-Mutka, 2011).

For educational purposes and curricula transformations this general understanding of the digital competence structure challenges the detailed description of its components which must differ according to education, learner occupation, age and many other criteria, among which there are transformations brought about by the constantly developing digital technologies.

A conceptual model of digital competencies by Martin \& Grudziecki (2015) provides some details of aspects of attitude (even if the authors do not distinguish between the aspects of content and character of cognition). These are the: intercultural, critical, creative, autonomous, responsible aspects. Attitudes include and demonstrate also the quality and content of its holder's thinking and self-conducted learning that allows for distinguishing between levels of digital literacy. These are digital competence (skills, concepts, approaches, attitudes, etc.), digital mastery usage (professional/ discipline application), and digital transformation (innovation, creativity). The model has prompted a need to address the pedagogical category of didactic principles, since a university process still functions on the basis of educator and learner value exchange within a background of targeted communication and cooperation. Educators operate with the study content in its capacity as a pedagogical tool but students operate with the content in its capacity as a transformable object of their activities, as well as with digital technologies that allow for their transformational usage and even initiate transformations. The essence of the educators' mission has not changed under the influence of the possibilities and the strong impact of digital technologies to enable students' self-directed learning. These make educators change the character of their assistance; and this can be achieved by educator attitude change to digital tools, educational process with digital tools and transformations brought about by digital tools. 
Another consideration is published by UNESCO (2014). This distinguishes between three broad categories of skills by addressing skill dynamics foundation/basic, specialized, and transversal skills - which are considered important for the development of well-rounded learners and are related to attitude dynamics and competencies accordingly. This also initiates considerable transformations of curricula to provide learners opportunities for critical and innovative thinking, development of interpersonal and organizational skills, intra-personal skills (e.g. self-discipline, enthusiasm, perseverance, self-motivation, etc.), global citizenship (e.g. tolerance, openness, respect for diversity, intercultural understanding, etc.), media and information literacy such as the ability to locate and access information, as well as to analyse and evaluate media content in addition or even instead of text-books and curricula.

A conceptual model of the digital competence that transforms tertiary curricula therefore includes:

a) instrumental skills and knowledge - operational and mediumrelated - important knowledge and understanding of the digital devices, their possibilities and skills of their usage in general and in educational settings in particular;

b) advanced knowledge and skills of digital tools, media application and usage outside the educational settings, strategic personal objectives in communication and collaboration, information management, further learning and problem-solving, meaningful participation, etc., in other words - usage of the digital tools in various situations where personalized values, critical thinking and creativity are challenged and added, and therefore demonstrate and further develop student and educator attitudes in communication, collaboration or cooperation;

c) attitudes as a component of an educator and student digital competence when operating with the digital tools demonstrate and further develop their quality of mind-creative, critical, autonomous, responsible, also demonstrate an attitude holder's social position, for instance, tolerance, intercultural relations, reciprocity etc.; responsible attitude should be among the didactic principles of tertiary education.

$21^{\text {st }}$ Century learning is closely related to digital technology and, accordingly, to the learner's and educators' digital competence. If properly designed and used technologies may enable student engagement in multisensory learning, successful performance, learning motivation and positive attitude. Students can interact with virtual objects at their own pace and make subjective sense of the perceived objective reality. Educators' choice of when and how to use technologies can be tailored to 
learners' characteristics and needs, therefore easily capturing their attention (Pantelidis, 2009). The virtual world becomes an excellent opportunity for educators to implement a learner-centered pedagogical approach where students learn by doing, which otherwise would be limited. Furthermore, another way to enhance students' fine visual-spatial skills is the possibility of modifying parameters that often cannot be changed in a real system (Potkonjak, et al. 2016). These, and also other useful qualities, are encountered if educators and students hold a positive or responsible attitude to progressive changes.

These conclusions and statements (among many others) of researchers have been applied in education as creative tools for enhancing traditional curricula and learning techniques to change the role of the learner by becoming a transformer of his knowledge rather than just a receiver of information (Sanabria \& Arámburo-Lizárraga, 2016), as well as a transformer of the ways of tertiary teaching-learning can enable changing roles among educators and students or teachers and learners. Effective and successful use of technologies coupled with the qualities of the 21st Century learning, attitude, and learning style personalize the virtual learning environments (Jena, 2016). These statements justify a tertiary didactic principle of learning in educator - student teams.

Curricula transformations are also a result of innovations encountered by educators and students and triggered by their attitudes. These further transform attitudes and lead to an appropriate environment for digital learning - virtual, face-to-face or mixed curriculum. Some of the advantages of virtual curriculum over the physical one include flexibility involving different components that can be easily created allowing damage and multiple access by students using the same virtual equipment at the same time. The virtual reality, for instance, aided by the $5 \mathrm{G}$ network (the fifthgeneration cellular network technology that provides broadband access) is considered to be able of providing an even more effective way of teaching by ensuring access to a new generation of technology that improves the efficiency of teaching infrastructure (Orlosky, et al., 2017); the 3D virtual environments can facilitate students' constructivist learning by providing flexible and unique learner-centered learning. Practitioners can also observe differences in educator and student attitude demonstrations like readiness, desire and willingness to transform the educational process or curriculum accordingly. In addition to these explorations, the educational process must address also such complicated phenomena as individual features of personality and self-image, cognitive ability and peculiarities of perception, experience and understanding - all these and other factors influence attitude to technologies that affect educator, as well as student, learning and competence development. The researchers of the above 
mentioned project consider relevant for tertiary education the principle of role exchange among educators and students to make better use of their priorities, especially the students' attitude and competence in the usage of digital technologies.

The term principles is a didactic category that introduces the basic theoretical statements and guidelines of creating and conducting an educator assisted tertiary process/curriculum. These become especially helpful to maintain the effectivity of a deliberately organized educational process in its intensive transformation. Therefore didactic principles accentuate learners' consciousness and activity in quality perception and competence acquisition, accessibility of education to meet students' needs and personalized educator assistance, facilitating student autonomous digital learning to make it transformative, etc. (more on didactic principles in the context of the technology-enhnced learning, Žogla, 2019). Principles of tertiary curriculum follow the logic of teaching-learning, as well as the logic of attitude development:

a) educators assist students' learning and saving time, successfully cover the program and their becoming self-directed learners by targeted usage of digital technologies;

b) multiple changes which are introduced by digital technologies invite educators to address their attitude to the changed mission, using the new possibilities and becoming digital learners themselves individuals do not have an attitude until they first encounter the attitude object or information about it and respond evaluatively (Eagly \& Chaiken, 1998).

Evaluation of educators' and students' attitudes towards digital technologies might prompt some ideas of transforming tertiary curricula towards more effective usage of e-environment by defining some didactic principles.

\section{Methodology}

The present paper uses the empirical data to trace if there are any significant differences in educators' and tertiary students' attitude to digital technologies (Gokhale et al., 2013; Hofstede et al., 2011; Sharma, 2009) and digital competence development, that might interfere with the transforming nature of technologies and therefore improvement of students' digital learning. The investigation used a questionnaire as a tool of data collection (Gokhale et al., 2013). The survey has been posted on the project website and tertiary students and educators of Latvia were addressed to give their views. The questionnaire addresses five positions which demonstrate educators' attitude to the digital technologies: 
- educators' and students' interest in learning about IT,

- recognition of the practical value of IT,

- observations of the possible negative impact of IT,

- gender equity or in-equity in using technologies,

- recognition of the positive impact of technologies on work and human life.

The research base is made up of 260 respondents: 205 students and 55 educators of Latvian higher education institutions, including 44 men and 213 women, 3 respondents did not indicate their gender. Evaluating the offered assertions and coding of the factors and their characterizing statements were based on the interpretation of the findings by using the Likert scale - the procedure which is proposed by the questionnaire methodology. As well, the Mann - Whitney test and Kruskal - Wallis test, were used for quantitative data processing in SPSS 25.0 to identify a statistical significance depending on the profile of the respondents. At the starting stage of the data processing, Cronbach's alpha coefficient for internal consistency was calculated; the obtained result ( $\alpha=.857$ ) indicates good internal consistency.

\section{Findings}

Statistically significant differences $(p<.05)$ in the self-assessments (Table 1) depending on the position of the respondents (student or educators), were found in the evaluations of two factors: Negative Impact of IT and Positive Effect of IT on Work-Life. In other factors, no significant differences related to the respondents' position were observed. The average scores indicate that both groups of respondents (students and educators) have an interest in IT; respondents are aware of the role of technologies in modern life and believe that gender equality is also provided and is not violated by their use.

Table 1. Respondents' assessment of attitudes towards IT factors

\begin{tabular}{|l|c|c|c|}
\hline \multirow{2}{*}{\multicolumn{1}{|c|}{ Factors }} & \multicolumn{2}{c|}{ Mean } & \multirow{2}{*}{$\begin{array}{c}\text { Statistical } \\
\text { significance (p) }\end{array}$} \\
\cline { 2 - 4 } & Students & Educators & .227 \\
\hline Interest in Learning about IT & 3,20 & 3,28 & .335 \\
\hline Practical value of IT & 3,73 & 3,77 & .000 \\
\hline Negative Impact of IT & 3,24 & 2,94 & .381 \\
\hline Gender Equality of IT & 4,02 & 3,99 & $\mathbf{. 0 4 6}$ \\
\hline Positive Effect of IT on Work Life & 3,46 & 3,31 & \\
\hline
\end{tabular}


The analysis of statistically significant differences identifies that students more often (Mean Rank 529.63) than educators (Mean Rank 486.46) emphasize the Positive Effect of IT on Work-Life, as evidenced by the group's average rating factor. The analysis of the characterizing statements of the factor and statistically significant differences according to the position of the respondents (Table 2) are revealed only when assessing the statement In general, IT will create more jobs than it eliminates: students evaluate this claim higher (Mean Rank 137.07) than the educators (Mean Rank 106, 02). Analysis of the average values shows that educators, in general, disagree with this statement; they are aware that the lack of digital competence will reduce successful career opportunities. Significant differences are found in assessing the negative and positive impact of IT on working life: in both cases, doctoral students give a higher evaluation.

Table 2. Assessment of the qualifying statements of the factor Positive Effect of IT on Work Life

\begin{tabular}{|c|c|c|c|}
\hline \multirow{2}{*}{ Statements } & \multicolumn{2}{|c|}{ Mean } & \multirow{2}{*}{$\begin{array}{l}\text { Statistical } \\
\text { significance } \\
\text { (p) }\end{array}$} \\
\hline & Students & Educators & \\
\hline $\begin{array}{l}\text { In general, IT will create more jobs than elimi- } \\
\text { nates }\end{array}$ & 3,10 & 2,71 & .004 \\
\hline Because of IT work will become more appealing & 3,60 & 4,49 & .199 \\
\hline $\begin{array}{l}\text { Family-friendly environments are more available } \\
\text { in IT occupations than others }\end{array}$ & 3,09 & 3,04 & .613 \\
\hline $\begin{array}{l}\text { Because of IT, there will be more opportunities } \\
\text { for the next generation }\end{array}$ & 4,03 & 4,02 & .794 \\
\hline
\end{tabular}

Students responses argue that statistically significant differences ( $\mathrm{p}=.008$ ) are found in the evaluations of With IT work will become more appealing, depending on the field of science in which they are studying: medical and healthcare students are more likely to emphasize the attractiveness of IT use in their workplaces (Mean Rank 114, 58), while this view is seldom found with the students of agricultural and forestry sciences (Mean Rank 2.00), as well as with the students of humanities and arts (Mean Rank 79.66).

Evaluations of Positive Effect of IT on Work-Life confirm that respondents motivate their recognition of the impact of IT on the work environment by improving their digital competence; also they consider that students' motivation might improve their activities in the chosen field of science and work.

The analysis of the Negative Impact of the IT factor shows that the students' rating is higher (Mean Rank 538.62) than the assessment of 
the educators' (Mean Rank 452.98), as evidenced by the group's average rating factor. Statistically significant differences were found in three-factor statements (Table 3). In all cases, the students' Mean Rank is higher if compared to that of the educators.

Table 3. Assessment of the qualifying statements of the Factor Negative Impact of IT

\begin{tabular}{|c|c|c|c|c|c|}
\hline \multirow[b]{2}{*}{ Statements } & \multicolumn{2}{|c|}{ Mean } & \multirow{2}{*}{$\begin{array}{l}\text { Statistical } \\
\text { signifi- } \\
\text { cance (p) }\end{array}$} & \multicolumn{2}{|c|}{ Mean Rank } \\
\hline & Students & Educators & & Students & Educators \\
\hline $\begin{array}{l}\text { IT makes our way of life } \\
\text { change too fast }\end{array}$ & 3,93 & 3,93 & .958 & 130,39 & 130,93 \\
\hline $\begin{array}{l}\text { Advancements in IT will } \\
\text { eventually destroy the earth }\end{array}$ & 2,83 & 2,45 & .021 & 135,85 & 110,55 \\
\hline $\begin{array}{l}\text { People would do better by } \\
\text { living simpler life without } \\
\text { so much IT }\end{array}$ & 3,04 & 2,65 & .010 & 136,50 & 108,13 \\
\hline $\begin{array}{l}\text { IT applications create an } \\
\text { artificial and inhuman way } \\
\text { of living }\end{array}$ & 3,18 & 2,71 & .001 & 137,91 & 102,89 \\
\hline
\end{tabular}

The findings show that students are more concerned about the increasing impact of IT. Perhaps this can be explained by the fact that educators use IT more in their professional field; if compared to students they are less affected by the digital technologies in their everyday lives. In their turn, students grew up in a digitized environment; their social contacts more often are virtual if compared to those of the educators. These assumptions need further detailed studies.

This implies that although IT is increasingly coming into all spheres of human life, including education and, for example, many of the studies highlight the benefits of learning by using digital tools (Sun, 2018; Weng et al., 2013), the direct student-educator connectivity is still considered important, it supports the achievement of its own goals, promotes social welfare and socialization in a particular environment (Arpino, \& de Valk, 2018; Siedlecki et al. 2014). Learning by using the platforms offered by IT is just one way of facilitating modern individualization and differentiation according to the educational needs of each student, which should not become the main or even the only way. Student responses show that although they have a strong interest in IT, they crave for natural, human relationships that should not disappear from the learning environment.

The analysis also found statistically significant gender differences in the assessments $(\mathrm{p}=.002)$. Women more often (Mean Rank 135.18) agree 
with the statement Advancements in IT will eventually destroy the earth than men (Mean Rank 99.07). There are also significant differences in student responses ( $p=.019$ ), depending on the field of study, statement IT makes our way of life change too fast evaluations: more worried about medical and health (Mean Rank 113, 97) and natural science (Mean Rank 96, 80) students, less often in the field of agriculture and forestry (Mean Rank 1.50) and in the field of humanities and arts (Mean Rank 85, 54). The educators demonstrate statistically significant differences in the assessment It makes our way of life change too fast $(\mathrm{p}=.012)$ : this aspect is more often of concern in the areas of science (Mean Rank 48, 50), seldom among the representatives of the agricultural and forest sciences (Mean Rank 1, 50).

The researchers' attention has been attracted by the evaluation related to the respondents' motivation, a need and the importance for non-stop improvement of their digital competence (Table 4).

Table 4. Respondents' interest in the development of their digital competence

\begin{tabular}{|c|c|c|c|c|}
\hline \multirow[t]{2}{*}{ Statements } & \multirow[t]{2}{*}{ Mean } & \multirow[t]{2}{*}{$\begin{array}{l}\text { Agree } \\
(\%)\end{array}$} & \multicolumn{2}{|c|}{$\begin{array}{c}\text { Significance of } \\
\text { differences (p) } \\
\text { according to }\end{array}$} \\
\hline & & & gender & position \\
\hline $\begin{array}{l}\text { It is important for me in my daily life to know } \\
\text { about IT }\end{array}$ & 3,82 & 68,1 & .079 & .260 \\
\hline $\begin{array}{l}\text { IT courses make significant contribution to one's } \\
\text { education }\end{array}$ & 3,91 & 74,3 & .632 & .060 \\
\hline I enjoy learning about new IT discoveries & 3,57 & 55,0 & .031 & .447 \\
\hline $\begin{array}{l}\text { I am interested in new applications of IT for im- } \\
\text { proving our lives }\end{array}$ & 3,43 & 52,7 & .027 & .941 \\
\hline I like to read about IT-related topics & 3,07 & 34,6 & .000 & .514 \\
\hline $\begin{array}{l}\text { I have looked for information about IT advances } \\
\text { on the Internet }\end{array}$ & 3,02 & 39,2 & .000 & .031 \\
\hline
\end{tabular}

The findings show that most respondents are aware of the need for digital competence and its continuous improvement. Men do it more independently - they are more likely than women to be interested in new applications, searching and reading information. Statistically significant differences were found in the attitudes towards IT courses as a contribution to self-education, depending on the field of science. In student responses ( $\mathrm{p}=.035$ ) the effectiveness of courses is more often recognized by these in engineering (Mean Rank 128, 25) and sciences (Mean Rank 124, 70), 
less often by medical and health care students (Mean Rank 95, 26) and by agriculture and forestry students (Mean Rank 1. 50).

The educators' evaluations demonstrate statistically significant differences $(\mathrm{p}=.019)$ for this statement: the highest rating is given by the engineering educators (Mean Rank 42. 90), the lowest - by agriculture and forestry (Mean Rank 1. 00), also of humanities and arts (Mean Rank $15,67)$. The results suggest that the level of digital competence differs across the fields of sciences; this peculiarity should be respected in curricula building. Daily activities in a particular area require not only a different level of competence but also influence the motivation for the development of digital competence.

Indirect information on positive motivation can be obtained from positive answers, like this: It is important for me to know about IT, IT makes work more attractive, IT courses are an important contribution to self-education, IT for future generations will have more opportunities, I am interested in the latest IT applications that could improve our lives.

Statistically significant differences $(\mathrm{p}=.031)$, depending on the position of the respondents, indicate that educators (Mean Rank 149,12) are more likely to look for information about IT development on the Internet than students (Mean Rank 125,50). This makes it possible to conclude that teachers who usually are older than students would need more support in acquiring new IT possibilities. Today's students are safer with IT, they learn a lot from learning by doing, experiential learning, through reflecting, and also from each other.

Analysis of the data obtained in the Latvian cultural environment demonstrates differences in attitude towards IT; these were identified as being dependent on the profile and gender of respondents, also on positions and fields of sciences. Digital competence is perceived and understood by the respondents as a complex combination of knowledge, skills, attitudes, abilities, strategies; its complicated essence as well as assumption of the importance of IT and digital media for solving study, practice, research problems should be treated as a possibility of involving educators and students in effective communication, participation and cooperation to create and share new knowledge, deep understanding, acquiring new elaborate skills (Ferrari, 2012).

Additional research is needed to specify the level of digital competence for different groups of respondents (for instance, gender, profile, education, cultural context, etc.). This would allow for the identification of the educational needs of students and educators for the development of their digital competence consciously accept and appropriately meet the transformative impact of digital technologies. 


\section{Discussion}

The commonalities and difference between student and educator attitude development towards the digital technologies in education should be treated according to their positions in this process. The educators' job includes their particular responsibility, therefore their attitude to innovations and quality process must become a matter for their targeted self-education. Students' current values and needs obtain their specificity because of a large variety and innovative character of digital devices and their usage; these objects of their attitudes are influenced by particular situations and cultural contexts. In the digital age, students demonstrate a stronger disposition towards technologies if compared to their educators. This sign of the digital age demands the re-addressing of the didactic principles of formal educational settings (Žogla, 2019) and treat the differences in attitudes as priorities to be effectivelly used in education.

When creating an appropriate curriculum at least three positions relating the context of the studies and setting didactic principles should be addressed to reduce strong normative constraints and transform an indoctrinating process into a learner learning-centered one (principles could be described in details for each faculty, speciality etc.):

a) knowledge considered by students as valuable usually causes positive emotions and is manifested in actions, therefore principles of a tertiary educational process should make an appropriate shift because currently students hold wider knowledge and digital skills, therefore have larger potential for decision-making and curricula construction if compared to their real participation in these activities;

b) values and needs are usually embedded in a concrete reality by respecting students' individual differences that are significant and therefore reflected in their attitudes; students' digital competence should be considered their individual difference and a priority to be applied in a tertiary process;

c) instead of using special stimuli for students' learning, educators share their responsibilities with the students; roles of educators and students become interchangeable, threfore motivating.

The contextuality of educators' and students' values are demonstrated and implemented when coupled with their sense of freedom and responsible attitude while being in their respective positions with interchangeable roles. Meanwhile, both of them hold equal positions regarding their on-going learning - none of them can succeed by being passive in learning or by the normative restrictions of their positions. Transformation of educational curricula goes through the joint venture of educator and student value exchange or problem-solving using educator and student experiences and 
possibilities and breaking borders between students who, in normative settings prioritize students' features related to those of growing/developing persons (less experienced) and educators, who now prioritize their nonstop learning instead of prioritizing their experience.

Curricula of formal and informal/organized/assisted tertiary and further education do need clearly defined pedagogical approaches/ paradigms and educative goals which include a strong orientation towards responsible, critical, creative attitudes of future graduates to successfully meet the demands and priorities of their future jobs: graduates' and later employees' (also educators') appropriate personal qualities, if coupled with attitude development, become a precondition of targeted competence acquisition. Educational principles become the foundation for creating a model of students' and educators' attitude development to complete curricula transition. These can be grouped around the three levels of the digital competence, highlighting their essence, transformative character and demonstrating their step-by-step individual growth:

(a) instrumental level of competence as an ability to complete one's job;

(b) mastery level of this competence characterized by educators and graduates responsible attitude and ability to improve the educational and job process in particular and varied situations;

(c) educators' (future specialists of any area) expert level or even excellence in creative innovations that promote the development of a tertiary institution or tertiary education in general.

Therefore only reaching an instrumental level of competence in its traditional understanding for educators is not enough; this will stop a tertiary institution's development in its particular role.

The philosophical and psychological nature of attitudes prompts educators to prioritize attitudes and values to help students motivate their learning, and, when being learned, attitudes add to the learners' success and contribute to the development of even stronger attitudes. The foundations of educators' attitude to digital technologies and their usage should be readdressed with the focus on its changes in accordance with the possibilities which digital technologies provide in their capacity as educational tools. Exploring and using the transformational and transformative character of digital technologies that interfere with the educators' attitude leads to a higher general and unique qualities which a tertiary curriculum aims to nurture and which their further learning helps to keep balanced with new possibilities.

Educators' on-going investigations in cooperation with their students, coupled with the students' preferences and possibilities, as well as targeted changes of pedagogical tools for successful assistance constitute the core of a tertiary process driven by and initiating further educators' attitude 
change/development. Educator self-evaluation of their attitudes should be considered a part of their job to maintain high quality functioning; their targeted attitude development should be coupled with innovations to release synergy when educators and students mutually empower one another's development.

\section{References}

Ala-Mutka, K. (2011). Mapping Digital Competence: Towards a Conceptual Understanding. European Commission. Joint Research Centre. Institute for Prospective Technological Studies. ftp://jrc.es/pub/EURdoc/JRC67075_TN.pdf.

Allport, G. W. (1935). Attitudes. In: C. Murchison (Ed.). Handbook of Social Psychology, 2, (pp. 718-844). Worcester, MA: Clark University Press.

Al-Musawi, N. M., Al-Bustan, A. A., \& Al-Mezel, S. M. (2013). Developing a Scale to Measure Attitudes of University Students towards E-learning. In: Parmigiani, D., Pennazio, V. \& Traverso, A. (Eds.). (2013). Learning \& Teaching with Media \& Technology. ATEE-SIREM Winter Conference Proceedings. Association for Teacher Education in Europe, Rue Hobbema, 67, 1000 Brussels, Belgium.

Arpino, B., \& de Valk, H. (2018). Comparing the life satisfaction of immigrants and natives across Europe: the role of social contacts. Social indicators research, 137(3), $1163-1184$.

Chai, C. S., \& Kong, S. C. (2017). Professional learning for $21^{\text {st }}$-century education. Journal of Computers in Education, 4(1), 1-4.

Eagly, A. H., \& Chaiken, S. (1998). Attitude Structure and Function. In D. T. Gilbert, S. T. Fiske, \& G. Lindzey (Eds.). Handbook of Social Psychology (pp. 269-322). New York: McGraw-Hill.

European Commission (2019). Digital Competence Framework for Educators (DigCompEdu). Retrieved from https://ec.europa.eu/jrc/en/digcompedu.

Fazio, R. H. (1989). On the Power and Functionality of Attitudes.: The role of attitude accessibility. In A. R. Pratkanis, J. S. Breckler, A. G. Greenwald (Eds.). Attitude Structure and Function (pp. 153-179). Hillsdale, NJ: Lawrence Erlbaum Associates.

Ferrari, A. (2012). Digital competence in practice: An analysis of frameworks. Luxembourg: Publications Office of the European Union. DOI:10.2791/82116.

Gokhale, A. A., Brauchle, P. E., \& Machina, K. F. (2013). Scale to Measure Attitudes toward Information Technology. International Journal of Information and Communication Technology Education, 9(3), 13-26. DOI: 10.4018/jicte.2013070102.

Hoffman, C. (2019). „What is 5G, and how fast will it be?" How-To Geek web How-To Geek LLC. Retrieved: January, 23, 2019.

Hofstede, G. (2011). Dimensionalizing Cultures: The Hofstede Model in Context. Online Readings in Psychology and Culture, 2(1). https://doi.org/10.9707/2307-0919.1014.

Jena, R. K. (2016). Investigating the Interrelation between Attitudes, Learning Readiness, and Learning Styles under a Virtual Learning Environment: a study among Indian students. Behaviour \& Information Technology, 35(11), 946-957. https:// doi.org/10.1080/0144929X.2016.1212930. 
Lytras, M. D., Damiani, E., \& Mathkour, H. (2016). Virtual Reality in Learning, Collaboration, and Behavior: content, systems, strategies, context designs. Behaviour \& Information Technology, 35(11), 877-878.

Martin, A., \& Grudziecki, J. (2015). DigEuLit: Concepts and Tools for Digital Literacy Development. Innovations in Teaching and Learning in Information and Computer Sciences, (4), 246-264. https://doi.org/10.11120/ital.2006.05040249.

Orlosky, J., Kiyokawa, K., \& Takemura, H. (2017). Virtual and Augmented Reality on the 5G Highway. Journal of Information Processing, 25, 133-141. DOI: 10.2197/ ipsjjip.25.133.

Pantelidis, V. S. (2009). Reasons to Use Virtual Reality in Education and Training Courses and a Model to Determine when to Use Virtual Reality. Themes in Science and Technology Education, 2(1-2), 59-70.

Perloff, R. M., (2017). The Dynamics of Persuasion: Communication and Attitudes in the $21^{\text {st }}$ Century. Routledge. Retrieved from https://www.amazon.com/ Dynamics-Persuasion-Communication-Attitudes-Twenty-First/dp/1138100331/ ref $=$ dp_ob_title_bk.

Potkonjak, V., Gardner, M., Callaghan, V., Mattila, P., Guetl, C., Petrović, V. M., \& Jovanović, K. (2016). Virtual Laboratories for Education in Science, Technology, and Engineering: A review. Computers \& Fluids, 95, 309-327.

Pratkanis, A. R, Breckler, S. J., \& Greenwald, A. G. (2014). Exploring the Latent Structure of Strength-Related Attitude Attributes. Advances in Experimental Social Psychology, 38, $1-67$.

Redecker, Ch. (2018). DigCompEdu: The European Framework for the Digital Competence of Educators. The European Commission's Science and Knowledge Service. Joint Research Centre. DOI: 10.2760/159770.

Sanabria, J. C., \& Arámburo-Lizárraga, J. (2016). Enhancing 21st Century Skills with AR: Using the Gradual Immersion Method to Develop Collaborative Creativity. EURASIA Journal of Mathematics Science and Technology Education, 13(2): 487-501 DOI10.12973/ eurasia.2017.00627.

Siedlecki, K. L., Salthouse, T. A., Oishi, S., \& Jeswani, S. (2014). The Relationship Between Social Support and Subjective Well-being across Age. Social Indicators Research, 117(2), 561-576.

Segan, S. (2018). What is 5G? PC Magazine online. Retrieved from https://www.ericsson. com/en/5g/what-is-5g?gclid = EAIaIQobChMI2vqjosWp4gIVzOWaCh0tlw76EAAYASAA EgIWkPD_BwE.

Sun, K. (2018). Construction of" New Ecology" of Ideological and Political Education from the Perspective of Internet Socialization, Starting from the Education of Ideal and Belief of" Post-00s" College Students. 3rd International Conference on Contemporary Education, Social Sciences and Humanities (ICCESSH 2018), 278-281. https://dx.doi.org/ iccessh-18.2018.59.

UNESCO (2014). Skills for Holistic Human Development: Transversal skills. Education Policy Brief, 2: UNESCO, Bangkok (2014). https://unevoc.unesco.org/ go.php?q= TVETipedia + Glossary + A-Z\&id $=577$.

Weng, L., Ratkiewicz, J., Nicola Perra, N., Gonczalves, B., Castillo, C., Bonchi, F., Schifanella, R., Menczer, F., \& Flammini, A. (2013). The Role of Information Diffusion in the Evolution of Social Networks. Proceedings of the $19^{\text {th }}$ ACM SIGKDD international conference on Knowledge discovery and data mining, 356-364. 
Žogla, I. (2019). Principles of Learner Learning-Centred Didactic in the Context of Technology-Enhanced Learning. // Daniela, L. (Ed.). Didactics of Smart Pedagogy (pp. 71-94). Springer: Nature Switzerland AG 2019. https://doi.org/10.1007/978-3030-01551-0; DOI 978-3-030-01551-0_4, (C) 2019.

Žogla, I. (2017). Pedagoǵija and Educational Studies: competing traditions in the study of education in Latvia. In: Whitty, G. \& Furlong, J. (Eds.). Knowledge and the Study of Education - an international exploration. Oxford Studies sin Comparative Education (27)1, 103-124. Symposium Books. http://www.symposium-books.co.uk/. 